\title{
Bone Surface (Peripheral) Osteosarcoma
}

National Cancer Institute

\section{Source}

National Cancer Institute. Bone Surface (Peripheral) Osteosarcoma. NCI Thesaurus.

Code C7134.

A usually aggressive malignant bone-forming mesenchymal neoplasm arising from the surface of the bone. 